\title{
Synanthropic-dominated biomass in an insular landbird assemblage
}

\author{
C. Battisti \\ 'Torre Flavia' LTER (Long Term Ecological Research) Station, Protected Area Service, Città Metropolitana di Roma, \\ Via Tiburtina,691,00159Rome, Italy.E-mail: c.battisti@cittametropolitanaroma.gov.it
}

Keywords: Abundance/Biomass comparison, Body mass, Ecological guild, Sardinia, Small island.

\begin{abstract}
The effect of anthropization on sedentary landbirds occurring in late summer on a small Mediterranean island (San Pietro, SW Sardinia) has been studied comparing abundance and biomass among different ecological guilds. The two specialized insular guilds (Mediterranean warblers and rocky cliff species) represent about half of the total individual abundance (47\%) but only $16 \%$ in terms of biomass. Although almost all the surface of the island is covered by Mediterranean scrub (maquis), Mediterranean warblers were not as dominant as the guild of strictly synanthropic species. This latter guild was the most represented in frequency both for abundance and biomass. I hypothesize that (i) here the anthropization could be considered a locally relevant process disrupting the resource flow and lowering the trophic level and (ii) the dominance of synanthropic birds in terms of biomass could be a general phenomenon extended to a large set of Mediterranean islands. The three most abundant synanthropic species, linked to highly disturbed habitats, showed a larger body mass when compared to specialized species as Mediterranean warblers: when applying the Abundance/Biomass Comparison (ABC), an early cumulating biomass curve was observed, partially overlapping with abundance curve. This pattern did not match with the classic predictions for the $\mathrm{ABC}$ model (i.e., species with higher biomass are typical of undisturbed assemblage) and could be wrongly interpreted. Therefore, I suggest that the $\mathrm{ABC}$ assumptions are not universal but limited only to assemblages where high body mass species coincide to species of a higher trophic level.
\end{abstract}

Abbreviations: ABC-Abundance/Biomass Comparisons; RC-specialized Rocky Cliff nesting species; MW-Mediterranean Warblers; GR-diurnal Generalist Raptors; GI-Generalist Insectivorous species; SG-Small Granivorous species; SO-Strictly synanthropic species.

Nomenclature: del Hoyo et al. (1996); Peronace et al. (2012).

\section{Introduction}

Islands host peculiar species assemblages that are determined by random and deterministic biogeographic processes, both ecological and historical (MacArthur and Wilson 1967, Lomolino 2000, Thornton 2007, Whittaker and FernándezPalacios 2007). Among the historical factors, the anthropization process often drives the transformation of local ecosystems and changes the insular biodiversity (e.g., inducing both extinction of native and endemic taxa and introduction of non-native and synanthropic species; e.g., Terrell 1976, Case and Bolger 1991, Steadman 2006, Illera et al. 2016).

In the Mediterranean sea, the islands have been colonized and transformed by human activities since the Neolithic with significant consequences on the richness, abundance and diversity of local plant and animal communities (Schule 1993, Corti et al. 1999, Masseti 2009, Patton 2013; for a general arrangement: Blondel and Aronson 1999).

Birds represent a class of vertebrates widely studied in this sense, for their ease of sampling and the large number of species with different eco-biogeographic characteristics (Covas and Blondel 1998). In the Mediterranean area, many pieces of research have provided evidence of avian richness impoverishment with high species turnover due to the human activities occurring in the medium-long term (e.g., Milberg and Tyrberg 1993).
The extent of stress induced by anthropogenic activities on communities can be investigated through numerous analytical approaches such as the stress curves in Whittaker plots, the k-dominance plots, and the biomass abundance curves (review in Magurran and McGill 2011). For example, the distribution of species frequency in human-disturbed (i.e., anthropized) communities could show a low evenness, with a dominance of species highly abundant, of low trophic level and small body mass (reviews in Magurran 2004, Battisti et al. 2016).

In this work I investigated the effect of anthropization in a sedentary landbird assemblage on a small Mediterranean island characterized by a high naturalness associated with a long-term historical human presence. In this regard, I hypothesized that landbird assemblage is hardly affected by anthropization so that a large proportion of total density biomass belongs to synanthropic species. Since biomass is a good proxy of the resource use in presence of disturbance (Guo and Rundel 1987, Tokeshi 1993), I applied the Abundance/Biomass comparisons (ABC; Warwick 1986) to the relative frequencies in abundance and biomass obtained for an insular landbird assemblage. In this regard, I predicted that patterns obtained with this approach agree with the expectations for disturbed assemblages. To my knowledge, this is the first study applying this approach to vertebrates inhabiting small islands. 


\section{Materials and methods}

Study area

San Pietro Island is a circum-Sardinian island $(11 \mathrm{~km}$ off the South-Western coast; $\left.39^{\circ} 08^{\prime} \mathrm{N} ; 8^{\circ} 18^{\prime} \mathrm{E}\right)$ facing the Sulcis peninsula, with $51 \mathrm{~km}^{2}$ in size (the sixth largest island of Italy by area; Fig. 1). The island is of volcanic origin (Cioni and Funedda 2015). Since the high eco-biogeographic interest and conservation concern (e.g., Arrigoni and Bocchieri 1996, Bocchieri 2001), the San Pietro island is a Site of Community Importance ("ITB040027 SIC Isola di San Pietro"; 92/43/EU Directive)

The island is characterized mainly by a Mediterranean scrub (maquis with Erica arborea, Pistacia lentiscus, Genista ephedroides, Juniperus turbinata and Arbutus unedo; Erico-Arbutetum unedonis and Oleo lentiscetum-genistetosum associations). Mediterranean scrub is alternated with Mediterranean open prairies (Thero-Brachipodietea) and anthropogenic pinewood patches (Pinus pinaster, P. pinea, P. halepensis; further details in De Marco and Mossa 1980, Regione Sardegna 2005).

This island represents an important migratory stop-over for a large number of birds ( $>60$ species are included in 147/2009 'Birds' Directive; Regione Sardegna 2005) due to geographic location and the presence of habitats for resting, with largely available trophic resources. After a long period in which the island was uninhabited, starting from 1738 the island was colonized from a Ligurian population arriving from Tunisia (Vona et al. 1996). From the post-war period until today, a progressive tourist development led to an increase in urbanization, with rural houses scattered over most of the island. Actually, the inhabitants are mostly concentrated in Carloforte (about 6,000 inhabitants), the only town in the is- land (Pellerano and Rivano 1997, Pellerano 2001, Ruggeri 2003). Climate is typically Mediterranean.

\section{Experimental design}

Data were obtained by a modified line transect method (Bibby et al. 1992). All individuals were recorded by direct observation (using a binocular Leica 10x40) or listening to their songs, $50 \mathrm{~m}$ at left and right from the observer, assigning the value 1 at each song or visual contact.

I carried out 15 independent transects (total length: 53,600 m; range: 2,100-6,600 m; averaged length: 3,573.3 $\mathrm{m} \pm 1$,208.6), randomly distributed in a representative way along the whole territory of the island, excluding the urbanized areas of Carloforte town. Since I considered the insular landscape as environmentally homogeneous at the island scale (Mediterranean scrub with isolated pine wood patches and scattered houses; see study area), I considered each transect as a sampling unit and the whole of the transects as sampling comparable replications. Therefore, I grouped data for each transect in a single data-set, representing the whole insular landbird assemblage during the late summer season.

Excluding the town of Carloforte (where I have not used transects), there are no urbanized areas on the island but only relatively homogeneous maquis-habitats with rare scattered houses. Therefore, I have not performed a stratified sampling.

Each line transect I surveyed one time from 12 to 25 August 2017 for a total time of about 26 hours of sampling. Birds flying over the $50 \mathrm{~m}$ above the transect were not reported. I obtained the flight height by direct observation basing on an indirect trigonometric approach, measuring with a clinometer the angle between the flying birds and the orthogonal projection on the ground, then calculating the horizontal distance to the vertical axis.

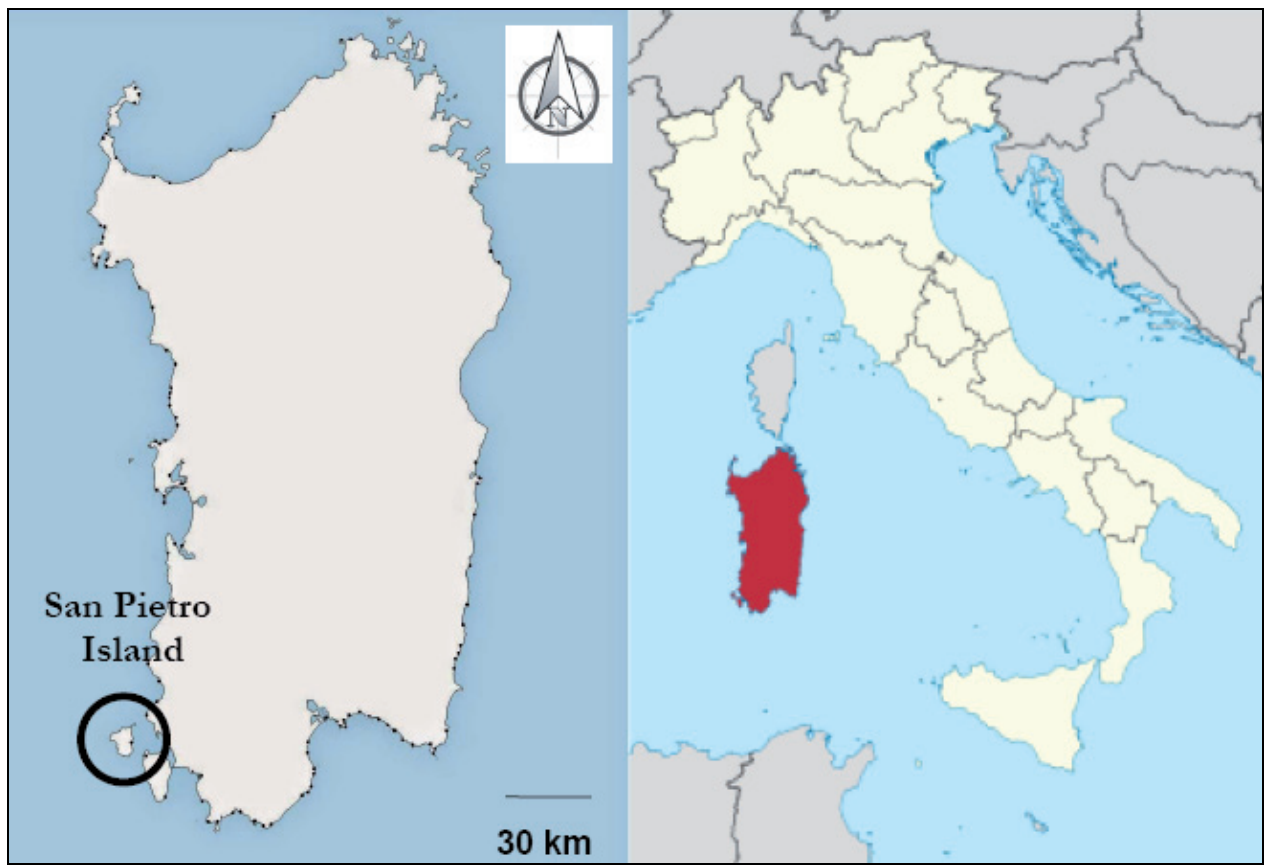

Figure 1. The study area (San Pietro Island, Sardinia, Italy). See text for details. 
I considered only sedentary landbirds, breeding on the island: therefore I excluded seabirds, including species occasionally occurring inside the island (e.g., Larus michahellis) and all the species using the island as migratory stopover (Muscicapa striata, Streptopelia turtur, Oenanthe sp., Saxicola sp.). The method utilized did not permit the observation of species with crepuscular and nocturnal activity: during the summer period many Mediterranean warblers (Sylvia melanocephala, S. undata, S. sarda, S. conspicillata), largely breeding in Sardinia in maquis habitats (Meschini and Frugis 1993, Grussu 2001) show a reduced singing frequency and more elusive behavior when compared to the spring period. Therefore the indirect taxonomic diagnosis (through vocal, alarm calls or singing emissions) of these syntopic individuals (see Cody and Walter 1976) can be difficult. Consequently, for these species we obtained only a value of number and frequency at guild level ('Mediterranean warblers'; see below).

The classic period indicated to carry out bird censuses is spring (Bibby et al. 1992), as birds can be easily detected during their breeding activities. However, in the Mediterranean islands that are part of an intense migratory pass (Berthold 2001), a census sampling in spring may lead to a bias in bird density estimation due to contemporary presence of either sedentary or migrant populations (both of them with singing individuals). Therefore summer could be a better period to selectively obtain data from sedentary populations, although our data could be less representative of the total density of individuals as they are detected only through alarm calls and songs.

\section{Data analyses}

For each species (and for the guild of Mediterranean warblers) I obtained the number of records $\left(\mathrm{n}_{\mathrm{i}}\right)$. This value was normalized to the total length of transects obtaining an abundance kilometric index $\left(\mathrm{AKI}_{\mathrm{i}}\right)$, expressed as individuals $/ \mathrm{km}$, and its relative frequency $\left(\mathrm{Fr}_{\mathrm{A}}\right.$ as $\mathrm{AKI}_{\mathrm{i}} / \mathrm{AKI}_{\text {tot }}$, where $\mathrm{AKI}_{\text {tot }}$ is the abundance kilometric index for all species).

For each species, I obtained the mean weight (from del Hoyo et al. 1996), calculating the biomass $\left(B_{i}\right.$ as mean weight of $i$-th species $\left.\times \mathrm{Fr}_{\mathrm{A}}\right)$, the biomass kilometric index $\left(\mathrm{BKI}_{\mathrm{i}}\right)$ and the relative frequency for each one $\left(\mathrm{Fr}_{\mathrm{B}}\right.$ as $\mathrm{BKI} \mathrm{I}_{\mathrm{i}} / \mathrm{BKI}_{\text {tot }}$, where $\mathrm{BKI}_{\text {tot }}$ is the abundance kilometric index for all species). Although the rock pigeon (Columba livia) and domestic pigeon (Columba livia domestic form) belong to the same species, I consider them as different taxa in this study because the former highly specializes on rocky cliffs and the latter relies on human buildings (Baldaccini et al. 2000, Battisti and Zapparoli 2011). Since I based this study using ecologicallyrelated guilds (see below), I think that this distinction is appropriate.

I grouped species in ecological guilds (sensu Verner 1984) subdividing them through a mixed criterion based on their (i) suitable habitat along a gradient of naturalness, from pristine (rocky cliffs and Mediterranean scrub) to intermediate anthropized habitats (pinewoods, mosaic and edge habitats), until highly anthropized (urbanized), and (ii) trophic level, from predators, to insectivorous to omnivorous/ herbivorous/granivorous (data from del Hoyo et al. 1996). I selected six guilds: (i) specialized rocky cliff nesting species (RC: Corvus corax, Columba livia wild form, Falco eleonorae); (ii) Mediterranean warblers (MW), mainly insectivorous and specialists linked to less disturbed maquis habitats; (iii) diurnal generalist raptors (GR: Falco tinnunculus, Buteo buteo), linked to landscape mosaic, (iv) generalist insectivorous species (GI: Turdus merula, Sylvia atricapilla), mainly insectivorous species locally linked to mosaic and pinewoodedge habitats; (v) small granivorous species (SG: Chloris chloris, Serinus serinus), linked to fringe-edge habitats; (vi) strictly synanthropic species (SO: Streptopelia decaocto, Columba livia domestic form, Corvus cornix), granivorous/ herbivorous/omnivorous species linked to highly anthropized habitats. For its extreme specialization, I considered specialized rocky cliff nesting as a unique guild, although having a different trophic level (both granivorous and predators).

The total relative frequency both for abundance $\left(\mathrm{Fr}_{\mathrm{A}}\right)$ and biomass $\left(\mathrm{Fr}_{\mathrm{B}}\right)$ was calculated at the species and guild level, but analyses were performed only at guild level.

To assess how these frequencies are distributed among guilds, I calculated an evenness index as $E=H^{\prime} / \ln (S)$ (Pielou 1969), where (i) H' is the Shannon diversity index as $-\Sigma$ Fr $\ln$ Fr (Shannon and Weaver 1963), both for abundance (respectively $\mathrm{E}_{\mathrm{A}}$ and $\mathrm{H}_{\mathrm{A}}{ }_{\mathrm{A}}$ ) and for biomass $\left(\mathrm{E}_{\mathrm{B}}\right.$ and $\left.\mathrm{H}^{\prime}{ }_{\mathrm{B}}\right)$, and (ii) $\mathrm{S}$ is the number of guilds.

Finally, I ranked the species from the most to the least important relative frequency, along a log-transformed $\mathrm{x}$-axis in a Cartesian space in order to obtain two better-fit curves (with equations and coefficient of determination, $\mathrm{R}^{2}$ ), both for abundance and biomass (Abundance/Biomass comparisons or ABC curves; Warwick 1986, Clarke 1990, review in Magurran 2004). When abundance and biomass curves are compared, information on the level of anthropogenic disturbance that affects the assemblages may be obtained. Indeed, the $\mathrm{ABC}$ curves are based on the assumption that in human-disturbed habitats, small-sized species (i.e., with low body weight and low trophic level) tend to increase in their abundance. Consequently, the abundance curves approach an asymptote before the biomass curves. On the contrary, in undisturbed habitats the opposite pattern may be observed, with the biomass curves cumulating before the abundance curves, an indication that a higher number of large-sized species of high trophic level occur in a more complex and diverse assemblages (Magurran 2004): in these conditions abundance frequencies are more evenly distributed when compared to biomass frequencies (i.e., evenness is higher in biomass frequencies). Early cumulating abundance curves may indicate that the resources are used by few dominant (i.e., more abundant) species with a broad spatial niche (i.e., generalist), while early cumulating biomass curves may indicate that the individuals with high body weight (and species with a high biomass) largely occur in the assemblage (Magurran 2004). Under intermediate circumstances, the biomass and abundance curves may overlap and cross each other (Clarke and Warwick 2001). To quantitatively assess differences between abundance and biomass curves, I performed a $\mathrm{W}$ statistic (Clarke 1990) as: $\mathrm{W}=\Sigma\left(\mathrm{Fr}_{\mathrm{B}}-\mathrm{Fr}_{\mathrm{A}}\right) / 50(\mathrm{~S}-1)$, where $\mathrm{S}$ is 
the number of guilds. $W$ ranges from -1 to +1 , with positive values if the biomass curve is consistently above the abundance curve, implying an undisturbed assemblage (Magurran 2004). On the contrary, negative values of W reveal an abundance curve consistently above the biomass curve, implying a disturbed assemblage. Overlapping biomass and abundance curves produce a $\mathrm{W}$ value of about zero, implying a moderate disturbance on the assemblage.

I performed (i) a $\chi^{2}$ test, to formally assess differences between biomass and abundance frequencies for each guilds and (ii) an Analysis of Covariance (ANCOVA; using abundance or biomass as the grouping variables and cumulative guild rank as a covariate), to test for differences between the better-fit regression lines in ABC approach (Dytham 2011). I used the SPSS v. 13.0 software (SPSS 2003). Alpha level was set at 0.05 .

\section{Results}

I obtained 326 records associated with six guilds $\left(\mathrm{AKI}_{\text {tot }}\right.$ $=6.08 ; \mathrm{BKI}_{\text {tot }}=1585.48$; for details at single species level, see Supplementary materials Appendix S1). The two specialized typically insular guilds (Mediterranean warblers and rocky cliff species) represent about half of the total individual abundance (47\%) but only $16 \%$ in terms of biomass. Strictly synanthropic omnivorous species appears in the guild with the highest total frequency both for abundance $\left(\mathrm{Fr}_{\mathrm{A}}=0.44\right)$ and, overall, for biomass $\left(\mathrm{Fr}_{\mathrm{B}}=0.715\right.$; Table 1). Although $\mathrm{Fr}_{\mathrm{A}}$ of Mediterranean warblers was not significantly different from that of strictly synanthropic species $\left(\chi^{2}=0.627\right.$, $\mathrm{p}=0.429)$, their $\mathrm{Fr}_{\mathrm{B}}$ is significantly lower $\left(\chi^{2}=1611.196\right.$, p $<0.001$; Fig. 2).

Mediterranean warblers and generalist insectivorous species showed a significantly higher frequency in abundance when compared to biomass; conversely strictly synanthropic omnivorous, small granivorous, generalist raptors and rocky cliff species showed a significantly higher biomass when compared to abundance (Table 1).
Evenness at the guild level is lower (and Shannon diversity is higher) considering the abundance $\left(\mathrm{E}_{\mathrm{A}}=0.666 ; \mathrm{H}_{\mathrm{A}}{ }_{\mathrm{A}}=\right.$ $1.193)$ when compared to biomass frequencies $\left(E_{B}=0.498\right.$; $\left.\mathrm{H}^{\prime}{ }_{\mathrm{B}}=0.892\right)$. ABC analysis shows the biomass curve located above the abundance curve (Fig. 3; polynomial better-fit curves; $\mathrm{R}^{2} \geq 0.90$ ): these two curves did not show a significant difference (ANCOVA: $\mathrm{F}_{1,9}=1.06, \mathrm{p}=0.330$ ) and this pattern is due only to the large difference between frequencies $\left(\mathrm{Fr}_{\mathrm{B}} \mathrm{vs} . \mathrm{Fr}_{\mathrm{A}}\right)$ for the first ranking guild (strictly synanthropic species; $\chi^{2}=87.945, \mathrm{p}<0.001$ ). W statistic value is 0 , indicating a moderate level of disturbance on the assemblage.

\section{Discussion}

Although studies on individual migratory species have been carried out in this circum-Sardinian island (e.g., Marchetti et al. 1996, Pilastro et al. 1998, Rosén et al. 1999,

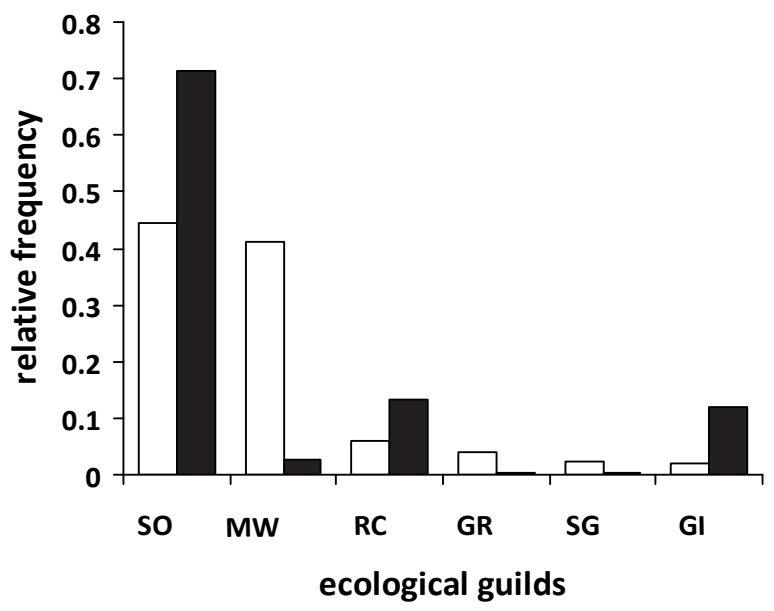

Figure 2. Comparisons between relative frequency in abundance (white columns) and biomass (black columns) for the guilds selected.

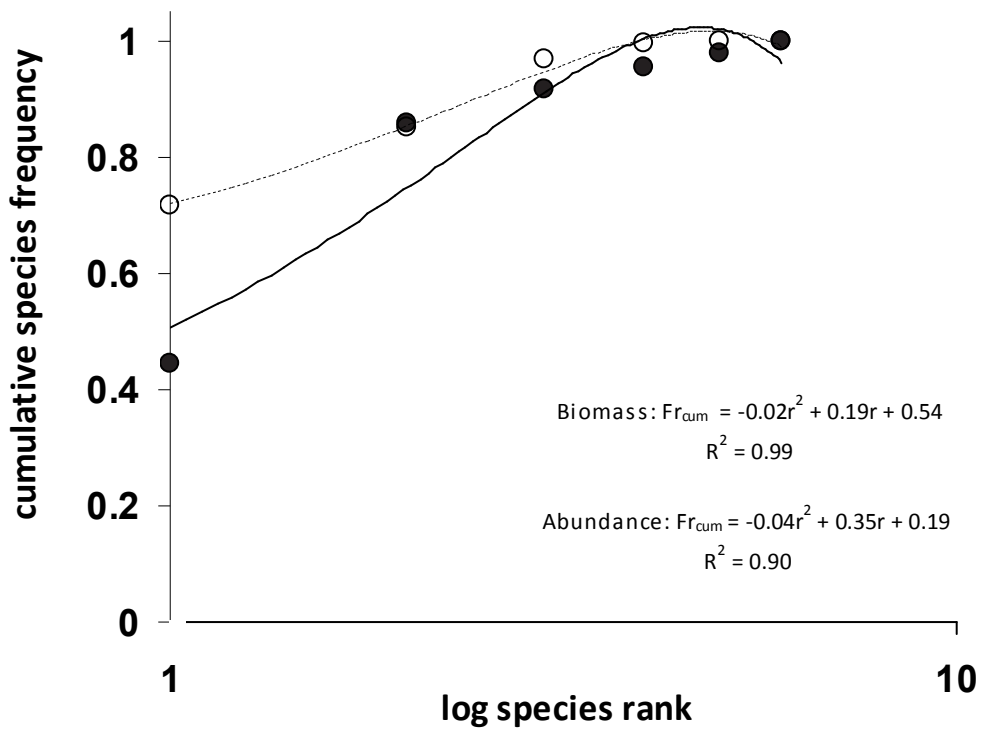

Figure 3. Abundance/Biomass comparison for the sedentary landbird assemblage. Biomass (in dashed line and white circles) and abundance better-fit (polynomial) curves (solid line and black cicles), line equations and coefficient of determination $\left(\mathrm{R}^{2}\right)$ are reported. 
Table 1. Abundance kilometric index $\left(\mathrm{AKI}_{\mathrm{G}}\right)$ and biomass kilometric index $\left(\mathrm{BKI}_{\mathrm{G}}\right)$, and their frequencies (respectively, $\mathrm{Fr}_{\mathrm{A}}$ and $\left.\mathrm{Fr}_{\mathrm{B}}\right)$ at the guild level. **<0.001. MW: Sylvia melanocephala, S. undata, S. sarda, S. conspicillata; GI: Turdus merula, Sylvia atricapilla; SO: Streptopelia decaocto, Columba livia domestic form, Corvus cornix, SG: Chloris chloris, Serinus serinus; GR: Buteo buteo, Falco tinnunculus; RC: Falco eleonorae, Columba livia, Corvus corax. Data at species level are reported in Supplementary materials 1.

\begin{tabular}{llcrrrr}
\hline & \multicolumn{1}{c}{ Guilds } & $\mathrm{AKI}_{\mathrm{G}}$ & \multicolumn{1}{c}{$\mathrm{Fr}_{\mathrm{A}}$} & \multicolumn{1}{c}{$\mathrm{BKI}_{\mathrm{G}}$} & \multicolumn{1}{c}{$\mathrm{Fr}_{\mathrm{B}}$} & \multicolumn{1}{c}{$\chi^{2}$} \\
\hline MW & Mediterranean warblers & 2.50 & 0.41 & 41.00 & 0.026 & $477.592^{* *}$ \\
GI & generalist insectivorous sp. & 0.13 & 0.02 & 7.32 & 0.005 & $8.598^{* *}$ \\
SO & strictly synanthropic sp. & 2.71 & 0.44 & 1133.81 & 0.715 & $87.945^{* *}$ \\
SG & small granivorous sp. & 0.15 & 0.02 & 2.74 & 0.002 & $20.452^{* *}$ \\
GR & generalist raptors & 0.24 & 0.04 & 187.69 & 0.118 & $16.959^{* *}$ \\
RC & rocky cliff species & 0.35 & 0.06 & 212.92 & 0.134 & $13.953^{* *}$ \\
\hline
\end{tabular}

Bianchi et al. 2008), quantitative research at community level on the sedentary birds are lacking and the present study is the first of this kind.

A first interesting result is that, although the dominant landscape matrix (about $80 \%$ of the island surface) is represented by a maquis (Mediterranean scrub), the guild of Mediterranean warblers strictly linked to this habitat is not as dominant as the guild of strictly synanthropic species. Moreover, the dominance of synanthropic (sensu lato) species could be underestimated. Indeed, excluding species of rock cliffs, most of the species belonging to the other guilds show an intermediate synanthropy: for example, the small granivorous species, partially linked to settlements and finegrained gardens (Quesada and MacGregor-Fors 2010), mosaic species as Falco tinnunculus linked to rural building for nesting (Salvati et al. 1999) and the generalist insectivorous also linked to planted pinewoods, gardens and suburban areas (Partecke et al. 2006, Evans et al. 2010).

When analyzing biomass, the role of strictly synanthropic species was further emphasized since almost $3 / 4$ of total biomass was assigned to these species. These species of low trophic level (omnivorous/herbivorous) significantly prevail in biomass when compared to insectivorous species (Mediterranean warblers and insectivorous generalists) and other guilds linked to pristine or less disturbed habitats (as specialized rocky cliff species). This concentration of biomass in a single guild is highlighted by the data on evenness: this parameter showed lower values in biomass when compared to abundance.

Biomass is a more effective measure of energy flow, resource use and resource apportionment than the abundance (Guo and Rundel 1987, Tokeshi 1993). Moreover, biomass of synanthropic species can be used as evidence of an ecological cycle disorder caused by anthropization (Nuorteva 1971, Lasiaka 1999, Solyanko et al. 2011). Therefore, I can suggest that in this small island (and, extending this case study, probably in a large number of other small and medium-sized Mediterranean islands) historical human presence acted as a relevant process, in particular (i) disrupting the energy and resource flow, and (ii) lowering the trophic level (now dominated by herbivory and omnivory). This human-dominated process could be relatively recent since these strictly synan- thropic species showed an expansion in their Mediterranean range in the last Century due to intrinsic (genetic) or extrinsic (environmental) factors. Streptopelia decaocto represents an example of a recent invasion from Eastern to Western and Southern Europe (Coombs et al. 1981, Hengeveld 1988, Eraud et al. 2007). This species is still conquering the south of Italy and islands, continuing a colonization that has begun several decades ago (Brichetti et al. 1986), favored, among other factors, by the spread of human settlements (TelliniFlorenzano et al. 2009). Corvus cornix is a generalist linked to highly anthropized habitats (e.g., urban areas: Sorace and Gustin 2009) with a process started in the $19^{\text {th }}$ Century due to urbanization at landscape level (Houston 1997, Vuorisalo et al. 2003). Columba livia lived for a long time in urban environments with a domestic form and largely expanded due mainly to food resource availability, behaviour plasticity and adaptation (Przybylska et al. 2012, Skandrani et al. 2016).

Regarding the comparison between cumulative abundance and biomass frequencies (ABC curves), a number of studies have been carried out in differently-characterized taxonomic- and ecological assemblages, both in invertebrates (zooplankton: Michaloudi et al. 1997, macrobenthos: Warwick 1986, Kaiser et al. 2000, DelValls et al. 1998, Roth and Wilson 1998; infratidal assemblages: Tuck et al. 1998, Campos-Vasquez et al. 1999) and vertebrates (freshwater fish: Penczak and Kruk 1999, Magurran and Phillip 2001; small mammals: Prete et al. 2012; reptiles: Smith and Rissler 2010), but never for birds. The key assumption of this approach is that disturbed assemblages will be characterized by dominant species (i.e., having a higher frequency) having a lower biomass when compared to undisturbed assemblage (Warwick 1986). Following this premise, when the disturbances occur the larger species are unlikely to be dominant and the distribution of biomass among species will be less even than the distribution of abundance: consequently, in a diagram reporting species frequencies on the y-axis and species rank on $\mathrm{x}$-axis, the biomass curve will lie below the abundance curve (Magurran 2004). Nevertheless, I suggest that when the ABC model is applied to peculiar assemblages a cautionary interpretation of the results is needed. Indeed, in our insular landbird assemblage the three most abundant strictly synanthropic species, although linked to disturbed 
(anthropized) habitats, show each one a larger body mass (and a lower trophic level) when compared to specialized species as Mediterranean warblers. Therefore, here we obtained a pattern where (i) biomass line is above the abundance curve, (ii) curves are not significantly different, and (iii) $\mathrm{W}$ statistic is 0 . Following the $\mathrm{ABC}$ assumptions, this pattern indicates a moderate level of disturbance. Nevertheless, this pattern is due only to presence of large synanthropic species of low trophic level linked to highly disturbed habitats, differently from other assemblages to which the $\mathrm{ABC}$ model was originally applied (i.e., where large body mass species are specialized and of higher trophic level, so indicating lack of disturbance; Magurran 2004). In this sense, this insular assemblage shows a paradoxical $\mathrm{ABC}$ pattern yet observed in other assemblages: indeed, differently from $\mathrm{ABC}$ assumptions, Prete et al. (2012) reported that in small mammal assemblages living in continental anthropized habitats, (i) synanthropic omnivorous species of low trophic level and high biomass (Rattus spp.) dominated in stressed contexts and (ii) small carnivorous (as shrews, Soricomorpha) of higher trophic level but very low body mass, associated to undisturbed habitats, are scanty (Prete et al. 2012). In these disturbed assemblages, the increase in abundance of large species with high body mass may correspond to early cumulating biomass curves that may be wrongly interpreted as typical of low disturbed assemblages. Data on evenness calculated at guild level support this consideration: contrary to expected, I observed a lower value of evenness for biomass when compared to abundance. This pattern is typically obtained in undisturbed assemblages but, in our case, it is due to the dominance of strictly synanthropic species (linked to disturbed environments).

A cautionary interpretation of $\mathrm{ABC}$ curves has been yet suggested for invertebrates (Warwick and Clarke 1994, Solyanko et al. 2011, Magurran 2004) and the present study presents a case in homeothermic vertebrates besides to small mammals (Prete et al. 2012). Therefore, the assumptions linked to the $\mathrm{ABC}$ curves (i.e., in disturbed assemblage species with higher biomass are less represented and biomass curve underlie the abundance curve) is probably not universal but limited only to assemblages where species with higher body mass have higher trophic level. In this regard, birds and mammals in anthropized (and, in our case, impoverished insular) contexts could be represented exceptions where ABC assumptions did not work. Moreover, the application in these contexts of Abundance/Biomass comparisons for birds and small mammals could imply a critical review of the general assumptions of this model.

It is important to underline some caveats that could have a role on the interpretation of the results. First, although this data set has been obtained carrying out an independent sampling on a representative surface of the study area, I have obtained a limited number in species and individuals since this study was carried out on a small island. Consequently, this fact could affect both the ABC pattern observed and the related statistic. However the low number of species and individuals represents a contingency related to the peculiar context investigated, so highlighting as the anomaly in the ABC pattern could be due not only to the taxa investigated but also to the insular context. Therefore, following the consideration of Smith et al. (2010), the applications of Abundance/Biomass Comparisons need to take into account both the specific ecological characteristics of studied taxa and the natural history of study sites to avoid incorrect interpretations of disturbance response. In this regard, our data support the hypothesis that also the geographical features of the study site (in this case, a small island) could act in explaining the patterns.

Secondly, our conclusions are only based on data from one island without any comparison. Therefore the observed pattern need to be corroborated by further studies from other small islands. In this regard, these exploratory results stimulate further research in other Mediterranean islands, characterized by a historical human presence but with different avian assemblages.

Finally, I carried out this study in a single season. It could be interesting to define an inter-seasonal sampling design, also including migrant and wintering species in order to test if our data are only season-specific or could be extended around a yearly cycle.

Acknowledgments: I wish to thank A. Zocchi for suggestions to the first draft of the manuscript and for a check of English style and language. Two anonymous reviewers and the Editor provided useful comments and suggestions who largely improved the first and the second version of the manuscript.

\section{References}

Arrigoni, P.V. and E. Bocchieri. 1996. Caratteri fitogeografici della flora delle piccole isole circumsarde. Biogeographia 18:63-90.

Baldaccini, N.E., D. Giunchi, E. Mongini and L. Ragionieri. 2000. Foraging flights of wild rock doves (Columba l. livia): a spatiotemporal analysis. Ital. J. Zool. 67:371-377.

Battisti, C. and M. Zapparoli. 2011. Sulla nomenclatura delle popolazioni urbane di Columba livia J.F. Gmelin, 1789: una revisione critica della letteratura in Italia. Avocetta 35:23-29.

Battisti, C., G. Poeta and G. Fanelli. 2016. An Introduction to Disturbance Ecology. A Road Map for Wildlife Management and Conservation. Springer, The Netherlands.

Berthold, B. 2001. Bird Migration. Oxford University Press, Oxford.

Bianchi, N., S. Ancora, N. Di Fazio and C. Leonzio. 2008. Cadmium, lead, and mercury levels in feathers of small passerine birds: noninvasive sampling strategy. Environ. Toxicol. Chem. 27:2064-2070.

Bibby, C.J., D. Burgess and D.A. Hill. 1992. Bird Census Techniques. Academic Press, London.

Bocchieri, E. 2001. Endemismi e rarità tra la flora delle piccole isole della provincia di Cagliari (Sardegna). Biogeographia 22:139168.

Blondel, J. and J. Aronson. 1999. Biology and Wildlife of the Mediterranean Region. Oxford University Press, Oxford.

Brichetti, P., N. Saino and L. Canova. 1986. Immigrazione ed espansione della Tortora dal collare orientale Streptopelia decaocto in Italia. Avocetta 10:45-49.

Campos-Vázquez, C., L.F. Carrera-Parra, N.E. González and S.I. Salazar-Vallejo. 1999. Criptofauna en rocas de Punta Nizuc, Caribe mexicano y su utilidad como biomonitor potencial. Rev. Biol. Trop. 47:799-808. 
Case, T.J. and D.T. Bolger. 1991. The role of introduced species in shaping the distribution and abundance of island reptiles. Evol. Ecol. 5:272-290.

Cioni, R. and A. Funedda. 2005. Structural geology of crystal-rich, silicic lava flows: a case study from San Pietro Island (Sardinia, Italy). Spec. pap., Geol. Soc. America 396:1.

Clarke, K.R. 1990. Comparisons of dominance curves. J. Exp. Mar. Biol. Ecol. 138:143-157.

Clarke, K.R. and R.M. Warwick. 2001. Change in marine communities: an approach to statistical analysis and interpretation. Plymouth Marine Laboratory, UK.

Cody, M.L. and H. Walter. 1976. Habitat selection and interspecific interaction among Mediterranean sylviid warblers. Oikos 27:210-238.

Coombs, C.F.B., A.J. Isaacson, R.K. Murton, R.J.P. Thearle and N.J. Westwood. 1981. Collared doves (Streptopelia decaocto) in urban habitats. J. Appl. Ecol. 18:41-62.

Corti, C., M. Masseti, M. Delfino and V. Pérez-Mellado. 1999. Man and herpetofauna of the Mediterranean islands. Rev. Esp. Herp. 13:83-100.

Covas, R. and J. Blondel. 1998. Biogeography and history of the Mediterranean bird fauna. Ibis 140:395-407.

DelValls, T.A., M. Conradi, E. Garcia-Adiego, J.M. Forja and A Gómez-Parra. 1998. Analysis of macrobenthic community structure in relation to different environmental sources of contamination in two littoral ecosystems from the Gulf of Cádiz (SW Spain). Hydrobiologia 385:59-70.

De Marco, G. and L. Mossa. 1980. Analisi fitosociologica e cartografica della vegetazione (1:25.000) dell'isola di S. Pietro (Sardegna sudoccidentale). Collana «Promozione della qualità dell'ambiente». CNR, Roma, 27 pp.

del Hoyo, J., A. Elliott and J. Sargatal (eds). 1996. Handbook of the Birds of the World. Lynx Edicions, Barcelona.

Dytham, C. 2011. Choosing and Using Statistics. A Biologist's Guide Wiley-Blackwell, UK.

Eraud, C., J.M. Boutin, D. Roux and B. Faivre. 2007. Spatial dynamics of an invasive bird species assessed using robust design occupancy analysis: the case of the Eurasian collared dove (Streptopelia decaocto) in France. J. Biogeogr. 34:1077-1086.

Evans, K.L., B.J. Hatchwell, M. Parnell and K.J. Gaston. 2010. A conceptual framework for the colonisation of urban areas: the blackbird Turdus merula as a case study. Biol. Rev. 85:643-667.

Grussu, M. 2001. Checklist of the birds of Sardinia. Aves Ichnusae $4: 2-55$.

Guo, Q. and P.W. Rundel. 1987. Measuring dominance and diversity in ecological communities: choosing the right variables. J. Veg. Sci. 8:405-408.

Hengeveld, R. 1988. Mechanisms of biological invasions. $J$ Biogeogr. 15:819-828.

Houston, D. 1997. Carrion Crow Corvus corone. In: Hagemeijer W.J.M., and M.J. Blair (eds), The EBCC Atlas of European Breeding Birds: The Distribution and Abundance. Tand AD Poyser, London, pp. 684-685.

Illera, J.C., L.G. Spurgin, E. Rodriguez-Exposito, M. Nogales and J.C. Rando. 2016. What are we learning about speciation and extinction from the Canary Islands? Ardeola 63:5-23.

Kaiser, M.J., K. Ramsay, C.A. Richardson, F.E. Spence and A.R. Brand. 2000. Chronic fishing disturbance has changed shelf sea benthic community structure. J. Anim. Ecol. 69:494-503.
Lasiaka, T. 1999. The putative impact of exploitation on rocky infratidal macrofaunal assemblages: a multiple-area comparison. J. Mar. Biol. Assoc., UK 79:23-34.

Lomolino, M.V. 2000. A species-based theory of insular zoogeography. Global Ecol. Biogeogr. 9:39-58.

MacArthur, R.H. and E.O. Wilson. 1967. The Theory of Island Biogeography. Princeton Univ. Press, Princeton.

Magurran, A.E. 2004. Measuring Biological Diversity. Blackwell Publishing, MA.

Magurran, A. E., and B.J. McGill (eds.). 2011. Biological Diversity: Frontiers in Measurement and Assessment. Oxford University Press, Oxford."

Magurran, A.E. and D.A. Phillip. 2001. Implications of species loss in freshwater fish assemblages. Ecography 24:645-650.

Marchetti, C., N.E. Baldaccini and D.P. Locatelli. 1996. Consistency and overlap of the diet of seven passerine trans-saharian migrants during spring stopover at two Mediterranean sites. Ital. J. Zool. 63:149-156.

Masseti, M. 2009. Mammals of the Mediterranean islands: homogenisation and the loss of biodiversity. Mammalia 73:169-202.

Meschini, E. and S. Frugis. 1993. Atlante degli uccelli nidificanti in Italia. Suppl. Ric. Biol. Selvaggina 20:1-346.

Michaloudi, E., M. Zarfdjian and P.S. Economidis. 1997. The zooplankton of Lake Mikri Prespa. Hydrobiologia 351:77-94.

Milberg, P. and T. Tyrberg. 1993. Naïve birds and noble savages: a review of man-caused prehistoric extinctions of island birds. Ecography 16:229-250.

Nuorteva, P. 1971. The synanthropy of birds as an expression of the ecological cycle disorder caused by urbanization. Ann. Zool. Fenn. 8:547-553.

Partecke, J., E. Gwinner and S. Bensch. 2006. Is urbanisation of European blackbirds (Turdus merula) associated with genetic differentiation? J. Ornithol. 147:549-552.

Patton, M. 2013. Islands in Time: Island Sociogeography and Mediterranean Prehistory. Routledge, London and New York.

Pellerano, L. and A. Rivano. 1997. Natura dell'isola di San Pietro. La flora. Edizioni della Torre, Cagliari.

Pellerano, L. 2001. L'ambiente marino e costiero dell'isola di San Pietro. Edizioni della Torre, Cagliari.

Penczak, T. and A. Kruk. 1999. Applicability of the abundance/ biomass comparison method for detecting human impacts on fish populations in the Pilica River, Poland. Fish. Res. 39:229-240.

Peronace, V., J.G. Cecere, M. Gustin and C. Rondinini. 2012. Lista Rossa 2011 degli uccelli nidificanti in Italia. Avocetta 36:11-58.

Pielou, E.C. 1969. An Introduction to Mathematical Ecology. WileyInterscience, New York.

Pilastro, A., S. Macchio, A. Massi, A. Montemaggiori and F. Spina 1998. Spring migratory routes of eight trans-Saharan passerines through the central and western Mediterranean; results from a network of insular and coastal ringing sites. Ibis 140:591-598.

Prete, S., C. Battisti, F. Marini and P. Ciucci. 2012. Applying abundance/biomass comparisons on a small mammal assemblage from Barn owl (Tyto alba) pellets (Mount Soratte, central Italy): a cautionary note. Rend. Lincei-Sci. Fis. 23:349-354.

Przybylska, K., A. Haidt, L. Myczko, A. Ekner-Grzyb, Z.M Rosin, Z. Kwiecinski, P. Tryjanowski, J. Suchodolska, V. Takacs, L. Jankowiak, M Tobólka, O Wasielewski, A. Graclik, A.J. Krawczyk, A. Kasprzak, O. Szwajkowski, P. Wylegala, A.W. Malecha, T. Mizera and O, Skórka. 2012. Local and landscapelevel factors affecting the density and distribution of the Feral Pigeon Columba livia var. domestica in an urban environment. 
Acta Ornithol. 47:37-45.

Quesada, J. and I. MacGregor-Fors. 2010. Avian community responses to the establishment of small garden allotments within a Mediterranean habitat mosaic. Anim. Biodiv. Conserv. 33:53-61.

Regione Sardegna. 2005. Piano di gestione del SIC "ITB040027 Isola di San Pietro". Available online: http://www.sardegnaambiente. it $/$ index.php? $x s l=612$ ands $=306725 \mathrm{andv}=2 \mathrm{andc}=14136$ andidsi to $=18$

Rosén, M., A. Hedenstrom, A. Badami, F. Spina and S. Akesson. 1999. Hunting flight behaviour of the Eleonora's falcon Falco eleonorae. J. Avian Biol. 30:342-350.

Roth, S. and J.G. Wilson. 1998. Functional analysis by trophic guilds of macrobenthic community structure in Dublin Bay, Ireland. $J$. Exp. Mar. Biol. Ecol. 222:195-217.

Ruggeri, R. 2003. Cronache inedite o poco note di alcuni fatti avvenuti in seguito all'invasione tunisina sull'isola di San Pietro (1798-1803). Edizioni della Torre, Cagliari.

Salvati, L., A. Manganaro, S. Fattorini and E. Piattella. 1999. Population features of Kestrels Falco tinnunculus in urban, suburban and rural areas in Central Italy. Acta Ornithol. 34:53-58.

Schule, W. 1993. Mammals, vegetation and the initial human settlement of the Mediterranean islands: a palaeoecological approach. J. Biogeogr. 20:399-411.

Shannon, C.E. and W. Weaver. 1963. Mathematical Theory of Communication. University of Illinois Press, Urbana, Illinois.

Skandrani, Z., A.C. Prevot, N.E. Baldaccini and J. Gasparini. 2016. On the interplay between phylogeny and environment on behaviour of two urban bird species, Columba livia and Corvus corone (Aves). Ital. J. Zool. 83:98-102.

Smith, W.H. and L.J. Rissler. 2010. Quantifying disturbance in terrestrial communities: abundance-biomass comparisons of herpetofauna closely track forest succession. Restor. Ecol. 18:195-204.

Solyanko, K., V. Spiridonov and A. Naumov. 2011. Biomass, commonly occurring and dominant species of macrobenthos in Onega Bay (White Sea, Russia): data from three different decades. Mar. Ecol.-Progr. Ser. 32:36-48.

Sorace, A. and M. Gustin. 2009. Distribution of generalist and specialist predators along urban gradients. Landscape Urban Plann. 90:111-118.

SPSS Inc. 2003. SPSS for Windows-release 13.0 (1st Sep 2004). Leadtools (c), Lead Technologies Inc

Steadman, D.W. 2006. Extinction and Biogeography of Tropical Pacific Birds. Univ. Chicago Press, Chicago.
Tellini-Florenzano, G., T. Campedelli, L. Buvoli, G. Londi and L. Mini. 2009. 20-year changes in the distribution patterns of Italian breeding birds. Avocetta 33:29-34.

Terrell, J. 1976. Island biogeography and man in Melanesia. Archaeol. Ocean. 11:1-17.

Thornton, I. 2007. Island Colonization. The Origin and Development of Island Communities. Cambridge University Press, Cambridge.

Tokeshi, M. 1993. Species abundance patterns and community structure. Adv. Ecol. Res. 24:112-186.

Tuck, I.D., S.J. Hall, M.R. Robertson, E. Armstrong and D.J. Basford. 1998. Effects of physical trawling disturbance in a previously unfished sheltered Scottish sea loch. Mar. Ecol.- Progr. Ser. 162:227-242.

Verner, J. 1984. The guild concept applied to management of bird populations. Environ. Manage. 8:1-13.

Vona, G., C.M. Calò, G. Lucia, G..E. Mameli, V. Succa, E. Esteban and P. Moral. 1996. Genetics, geography, and culture: the population of S. Pietro Island (Sardinia, Italy). Am. J. Phys. Anthropol. 100:461-471.

Vuorisalo, T., H. Andersson, T. Hugg, R. Lahtinen, H. Laaksonen and E. Lehikoinen. 2003. Urban development from an avian perspective: causes of hooded crow (Corvus corone cornix) urbanisation in two Finnish cities. Landscape Urban Plann. 62:69-87.

Warwick, R.M. 1986. A new method for detecting pollution effects on marine macro-benthic communities. Mar. Biol. 92:557-562

Warwick, R.M. and K.R. Clarke. 1994. Relearning the ABC: taxonomic changes and abundance/biomass relationships in disturbed benthic communities. Mar. Biol. 118:739-744.

Whittaker, R.J. and J.M. Fernández-Palacios. 2007. Island Biogeography: Ecology, Evolution, and Conservation. Oxford University Press, Oxford.

Received May 6, 2018 Revised July 9, August 18, 2018 Accepted September 4, 2018

\section{Supplementary material}

Appendix S1. Sedentary bird assemblage in the San Pietro island at species level.

The appendix max be downloaded from www.akademiai. com. 